\title{
SIMULAÇÃO EM SOFTWARE ARENA PARA ENTRADA DE CANA-DE-AÇÚCAR
}

\author{
SOFTWARE SIMULATION IN ARENA FOR SUGAR CANE INPUT
}

\author{
Valéria Aparecida Roque Rodrigues - valeriaroque2@gmail.com \\ Rhadler Herculani - rhadler.herculani@fateccbb.edu.br \\ Faculdade de Tecnologia de Bebedouro (Fatec) - Bebedouro - São Paulo - Brasil \\ DOI: 10.31510/infa.v17i1.735
}

\section{RESUMO}

O presente artigo trata de uma pesquisa em uma usina sucro-alcooleira que está evoluindo a cada ano, buscando melhoria continua em seus processos. Isso é percebido pelo aumento de sua produtividade e, na moagem atual, que está em torno de 14.000 toneladas em $24 \mathrm{hrs,} \mathrm{pode-se} \mathrm{ter}$ uma perda de sessenta mil reais em uma hora de parada. O objetivo deste trabalho é otimizar o tempo de entrada de cana de açúcar para a mesa de descarregamento, evitando perdas com a parada do processo na moagem. Para este estudo utilizou-se o método de cronometragem de tempo para melhorar o tempo de entrada de cana de açúcar na mesa de descarga tempo de pesagem, tempo de análise e tempo de mesa de descarga. O software de simulação ARENA é muito e eficaz para realizar estudos na área de tempos e métodos, além de demonstrar todo o processo de descarregamento de maneira simples através de um fluxograma. Permitindo tomadas de decisão e redução de gargalos do processo, sendo de suma importância para melhoria de todos os processos.

Palavras-chave: Usina. Processo. Descarga.

\begin{abstract}
This article deals with research in a sugar-alcohol plant that is evolving every year, seeking continuous improvement in its processes. This is noticed by the increase in its productivity and, in the current grinding, that is around 14,000 tons in 24 hours, you can have a loss of sixty thousand reais in one hour of stoppage. The objective of this work is to optimize the time of entry of sugar cane to the unloading table, avoiding losses with the stop of the process in the grinding. For this study, the method of timing was used to improve the time of entry of sugar cane into the unloading table, weighing time, analysis time and unloading table time. The ARENA simulation software is very and effective to carry out studies in the area of times and methods, in addition to demonstrating the entire download process in a simple way through a flowchart. Enabling decision making and reducing bottlenecks in the process, being of paramount importance for the improvement of all processes.
\end{abstract}

Keywords: Power plant. Process. Discharge. 


\section{INTRODUÇÃO}

Segundo Novacana (2013), a cana-de-açúcar é conhecida por suas características como uma planta fina de formato cilíndrico, folhas grandes e pode alcançar até seis metros de altura. É com ela que se faz açúcar, etanol e com a retirada do caldo sobra o bagaço que é utilizado na cogeração de energia, produtos essenciais na sobrevivência e para a economia mundial, dela se aproveita tudo.

A cana-de-açúcar é uma das principais culturas do mundo, cultivada em mais de 100 países, com a proximadamente 1.700 milhões de toneladas de cana-de-açúcar são produzidas anualmente em 24 milhões de ha em todo o mundo e representa uma importante fonte de mão de obra no meio rural nesses países (YARABRASIL, 2020).

No Brasil, a safra da cana de açúcar são em dois períodos, de abril a novembro no CentroSul e de setembro a março no Norte-Nordeste, o país produz etanol, açúcar e energia praticamente o ano todo.

O estado de São Paulo produz quase 60\% da cana de açúcar (NOVACANA, 2013).

A usina pesquisada está evoluindo a cada ano, buscando melhoria continua em seus processo e, segundo fontes internas, a cada ano sua produtividade aumenta e na moagem atual, que está em torno de 14.000 toneladas em 24 hrs, pode-se haver uma perda de R $\$ 60.000,00$ em 1 hora de parada.

O objetivo deste trabalho é propor a otimização do tempo de entrada de cana de açúcar e da mesa de descarregamento, para se previnir perdas com a constante parada do processo de entrada de matéria prima.

\section{EMBASAMENTO TEÓRICO}

\subsection{Histórico de Simulação}

Segundo Herculani et al. (2017, p. 178) com o surgimento do informática nos anos 50, “as modelagens de filas podem ser analisadas através da simulação que consiste em um processo que permite a obtenção de conclusões sobre o comportamento de um sistema, a partir da tentativa de imitar o funcionamento do sistema real através de um modelo". Dentro da simulação, é possível "a 
análise de cenários e assim a verificação de soluções de problemas do cotidiano em profundidade".

Em 1982, com a chegada dos computadores do tipo PC (Personal Computer), foi lançada a primeira versão da linguagem de simulação SIMAN, que foi desenvolvida pela Systems Modelyng Corporation (EUA), inspirada na linguagem GPSS usada em computadores de grande porte. A ideia era inovadora e foi a primeira linguagem específica de simulação destinada a IBM PC compatíveis. (PRADO, 2010)

Segundo Prado (2014), lançado o pacote CINEMA em 1990, pela mesma empresa, que, integrado ao SIMAN, "permitia apresentar uma representação animada e em cores do funcionamento do sistema. Sendo inovadora mais uma vez, sendo a primeira interface do tipo para simulação".

Segundo Araldi (2013), “em 1993, SIMAN e CINEMA evoluiram e foram integrados em um ambiente único de simulação que unia e potencializava seus recursos, o software ARENA. A linguagem SIMAN, através do software ARENA, passou a ser representada em formato gráfico", tornando os projetos de simulação intuitivos e agradáveis.

No ano de 1995, a Systems Modeling lançou a primeira versão do software ARENA para Windows 95 que foi também a "primeira ferramenta de simulação a trabalhar em 32 bits, uma tecnologia avançada para a época. No ano seguinte, com a versão 3.0, passou a ser a primeira e única até o momento a receber a certificação "Microsoft Windows Compatible", integrando a linguagem VBA", totalmente compatível com todos os "aplicativos do Microsoft Office e muitos outros" (WIKIPEDIA, 2020).

Segundo Araldi (2013), “com a compra da Systems Modeling pela gigante Rockwell em 2000, o software ARENA recebeu um enorme impulso de desenvolvimento, recebendo um grande investimento e novas versões agregando melhorias que são lançadas em intervalos de tempo cada vez mais curtos".

Nessa mesma época, o ARENA foi integrado pela suíte RS BIZWARE, "que reúne uma solução integrada e completa para projetar, planejar e gerenciar o chão de fábrica. Assim, o ARENA agora é parte importante da estratégica de atuação da Rockwell Software, braço de software da Rockwell, dentro do segmento de MES (Manufacturing Execution System)" (WIKIPEDIA, 2020). 


\subsection{ARENA e Input Analyser}

O ARENA é um software usados em simulações de tempos buscando melhorar os processos de uma empresa com custo baixo.

Na figura 1, vê-se seus módulos.

Figura 1 - Módulos do ARENA

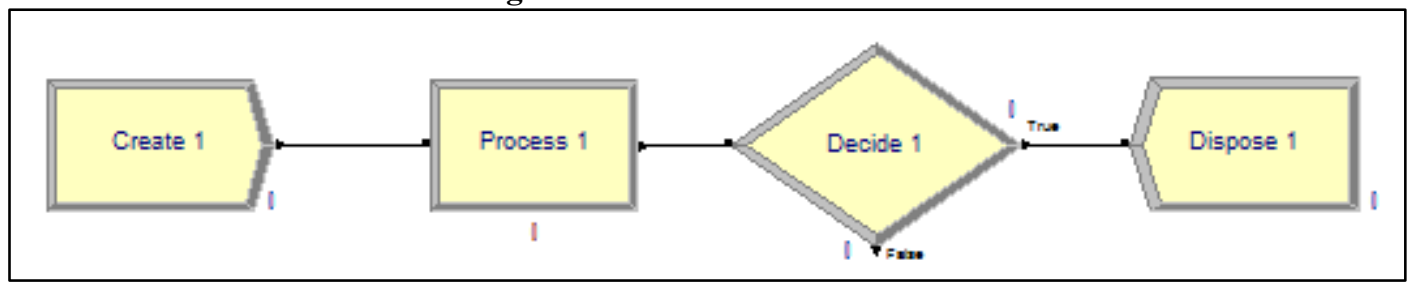

Fonte: Elaborado pelas autores

Os módulos da figura 1 são:

- Create: Segundo Herculani et al. (2017), é o início da simulação para uma entidade que move pelo modelo, buscando recursos e executando procedimentos lógicos;

- Process: Segundo Costa. e Pereira (2009), este módulo destina-se como o principal método de processamento na simulação. Opções para apreensão e liberação de recursos disponíveis. Além disso, existe a opção de usar um submodelo. O tempo do processo é atribuído à entidade e pode ser considerado como valor adicionado, valor não-adicionado, transferência, espera ou outras;

- Decide: Segundo Costa. e Pereira (2009), este módulo permite a tomada de decisões no sistema. Ele inclui opções para tomar decisões baseadas em uma ou mais condições ou com base em uma ou mais probabilidades. As condições podem ser baseadas em valores de atributos (por exemplo, prioridade), os valores das variáveis (por exemplo, número negado), o tipo de entidade, ou uma expressão (por exemplo, NQ (ProcessA.Queue));

- Dispose: Segundo Costa. e Pereira (2009), este módulo destina-se como ponto final para as entidades em um modelo de simulação. Ao clicar duas vezes neste módulo, aparecerá a caixa de entrada mostrada abaixo;

O ARENA possui uma ferramenta de entrada de dados, o Input Analyser que, segundo 
Costa. e Pereira (2009), é usado para qualidade de funções de distribuição de probabilidade aos dados de entrada, ajustar funções de distribuição específicas, para um arquivo de dados efetuando comparações nas funções de distribuição mostrando mudanças em parâmetros na mesma distribuição, gerar conjunto de dados aleatórios.

\subsection{Processos das Usinas Sucroalcooleiras}

\subsubsection{Balança de Entrada}

O processo se inicia na chegada de uma balança rodoviária, onde o caminhão chega com a matéria prima, este caminhão chega com todos os dados referente a frente de colheita, código do fornecedor registrado no sistema, equipamentos que executaram o carregamento (NOVACANA, 2013).

Estes dados são integrados por dois sistemas, o primeiro capta as informações via satélites por torres ou GPRS nas frentes de colheitas e transmite para o computador de bordo do caminhão.

Ao chegar na balança o computador de bordo que está dentro do caminhão automaticamente envia as informações das frentes via antena Zigbee, inegra com o ERP utilizado. O balanceiro confere todos os dados integrados com o que ele possui em seu sistema., após conferência capta o peso e grava.

Ao gravar o próprio sistema informa se vai analisar uma ou todas as unidades do caminhão ou se não vai analisar.

O sistema já é configurado com o tamanho da área que aquele caminhão veio e busca a quantidade que já foi analisada. Esta configuração é feita conforme as normas da Consecana.

\subsubsection{Furador}

Segundo Novacana (2013), após pesar e sair para análise, o caminhão segue para o furador para coletar amostra da cana. Ao chegar no furador, o motorista posiciona o caminhão em baixo da sonda conforme impresso no ticket, para analisar uma unidade, o motorista desce do caminhão entrega o ticket para o analista da sonda, e coloca a chave do caminhão no balcão. A 
sonda é automática em cada unidade coleta amostra, leva para o triturador, após triturada e feito a separação do material para análise, o analista libera o semáforo com a luz verde, isso se repete a cada unidade analisada, o motorista tem que posicionar o caminhão e descer do caminhão a cada unidade analisada, após este procedimento ele pega a chave e direciona o caminhão para aguardar o descarregamento.

\subsubsection{Mesa de Descarregamento}

Após ser liberado da sonda, o caminhão vai para o pátio aguardar a liberação para o descarregamento na mesa da moenda. O motorista tem que estar atento pois assim que um caminhão sai da mesa o outro caminhão tem que entrar em seguida (NOVACANA, 2013).

O caminhão entra na mesa da moenda, o funcionário engata os ganchos na carreta, esse processo é manual e inicia o descarregamento da cana de açúcar, este procedimento é feito unidade por unidade, o caminhão é liberado ao terminanr o descarregamento assim que a luz verde do semáforo acender finalizando o processo.

\section{DESENVOLVIMENTO DA TEMÁTICA}

No presente artigo, foram utilizadas pesquisas bibliográficas em livros, revistas e sites da internet. A pesquisa teve caráter quantitativo, foi realizada em forma de estudo de caso, houve a aplicação da metodologia de estudos de tempos e métodos e o uso do software de simulação ARENA para simular a realidade de uma linha de produção da empresa e propor melhorias, caso sejam necessárias.

A linha de produção escolhida pertence a uma usina de cana de açúcar, produzindo açúcar e álcool em grandes quantidades diariamente. Foram analisados os processos iniciais da produção que envolvem a pesagem do caminhão carregado na balança, o recolhimento de amostra de canade-açúcar por furador e o descarregamento do caminhão em uma esteira transportadora conhecida na fábrica como mesa. Os setores seguem essa sequência respectivamente. Foram coletados, em cada setor, 20 tempos em um período de 02 dias. Utilizando-se os tempos do sistema, para depois aplicar os tempos no software ARENA versão 15. 
A usina processa diariamente em média 14.000 toneladas de cana de açúcar. O setor da balança possui um funcionário por turno pesando todos os caminhões na entrada e na saída de produtos acabados. O setor do furador conta com um funcionário acompanhando a sonda, pegando os tickets, liberando o semáforo e retirando os bagaços do triturador. Já o setor de descarregamento possui um funcionário para engatar os ganchos nas carretas para o descarregamento. Os tempos no setor da balança foram coletados desde a entrada da balança até finalizarem a pesagem; no setor do furador, a coleta foi desde a fila do furador até a liberação do semáforo; para o setor de descarregamento, foram coletados desde o aguardo do descarregamento até a saída da mesa (local onde a cana é coletada para o transporte às moendas). Os tempos foram listados conforme a figura a seguir: 
Figura 2 -Planilha com os tempos de cada setor do processo

\begin{tabular}{|c|c|c|c|c|c|c|}
\hline Amostras & $\begin{array}{l}\text { Balança } \\
\text { Entrada }\end{array}$ & $\begin{array}{l}\text { Bal. } \\
\text { Entrada(seg.) }\end{array}$ & Furador & \begin{tabular}{|l} 
Furador \\
(seg.)
\end{tabular} & $\begin{array}{l}\text { Descarregamento } \\
\text { - Mesa }\end{array}$ & $\begin{array}{l}\text { Descarregamento } \\
\text { - Mesa (seg.) }\end{array}$ \\
\hline 1 & $00: 08: 38$ & 518 & $00: 22: 05$ & 1325 & $00: 38: 07$ & 2287 \\
\hline 2 & 00:03:49 & 229 & $00: 12: 19$ & 739 & $00: 42: 55$ & 2575 \\
\hline 3 & $00: 03: 40$ & 220 & 00:12:49 & 769 & $00: 53: 08$ & 3188 \\
\hline 4 & $00: 04: 36$ & 276 & 00:13:21 & 801 & $00: 56: 21$ & 3381 \\
\hline 5 & $00: 04: 11$ & 251 & $00: 10: 28$ & 628 & $00: 36: 07$ & 2167 \\
\hline 6 & $00: 07: 54$ & 474 & $00: 15: 31$ & 931 & $00: 59: 31$ & 3571 \\
\hline 7 & 00:09:00 & 540 & $00: 21: 32$ & 1292 & $00: 56: 50$ & 3410 \\
\hline 8 & $00: 04: 52$ & 292 & 00:11:48 & 708 & $00: 54: 07$ & 3247 \\
\hline 9 & 00:06:09 & 369 & $00: 11: 36$ & 696 & $00: 32: 31$ & 1951 \\
\hline 10 & $00: 04: 27$ & 267 & 00:19:09 & 1149 & $00: 59: 17$ & 3557 \\
\hline 11 & $00: 08: 58$ & 538 & $00: 22: 05$ & 1325 & $00: 37: 53$ & 2273 \\
\hline 12 & $00: 03: 21$ & 201 & 00:09:43 & 583 & $00: 42: 44$ & 2564 \\
\hline 13 & $00: 04: 43$ & 283 & 00:11:40 & 700 & $00: 25: 11$ & 1511 \\
\hline 14 & $00: 04: 33$ & 273 & 00:11:54 & 714 & $00: 32: 43$ & 1963 \\
\hline 15 & 00:08:16 & 496 & 00:24:41 & 1481 & 00:39:39 & 2379 \\
\hline 16 & $00: 05: 12$ & 312 & $00: 32: 20$ & 1940 & $00: 23: 51$ & 1431 \\
\hline 17 & $00: 03: 24$ & 204 & 00:08:24 & 504 & $00: 30: 04$ & 1804 \\
\hline 18 & $00: 03: 26$ & 206 & 00:06:58 & 418 & $00: 34: 57$ & 2097 \\
\hline 19 & $00: 02: 50$ & 170 & $00: 14: 14$ & 854 & $00: 36: 42$ & 2202 \\
\hline 20 & $00: 06: 55$ & 415 & $00: 10: 15$ & 615 & $00: 46: 20$ & 2780 \\
\hline
\end{tabular}

Fonte - Elaborado pelos Autores

\subsection{Acompanhamento Estatístico dos Dados}

Como foi mencionado, os processos são divididos por setores distintos e com atividades diferentes, mas um depende do outro. Para realizar a retirada de tempos, foi escolhido aleatoriamente os horários por turno, são 3 turnos de 8 horas. 
Para processamento de tempos de cada setor, foi utilizada a ferramenta Input Analyser, os tempos foram inseridos em base de dados, calculado a expressão estatística para ser lançada no simulador ARENA.

Os tempos serão calculados por setores distintamente, cada um irá gerar uma expressão diferente.

\subsubsection{Processo de tempos na Balança de Entrada}

No setor balança de entrada onde inicia o processo, o processo é pesar a cana de açúcar, pelo próprio funcionário sendo a maior parte automático, com um funcionário por turno, onde confere todos os dados integrados, em média pesa um caminhão entre 3 e 4 minutos. Com um total de 20 tempos levantados, a expressão gerada através do Input Analyser foi: Distribuição: Exponencial e Expressão $170+$ EXPO (0), conforme a figura 3 .

Figura 3 - Tempos da Balança de Entrada

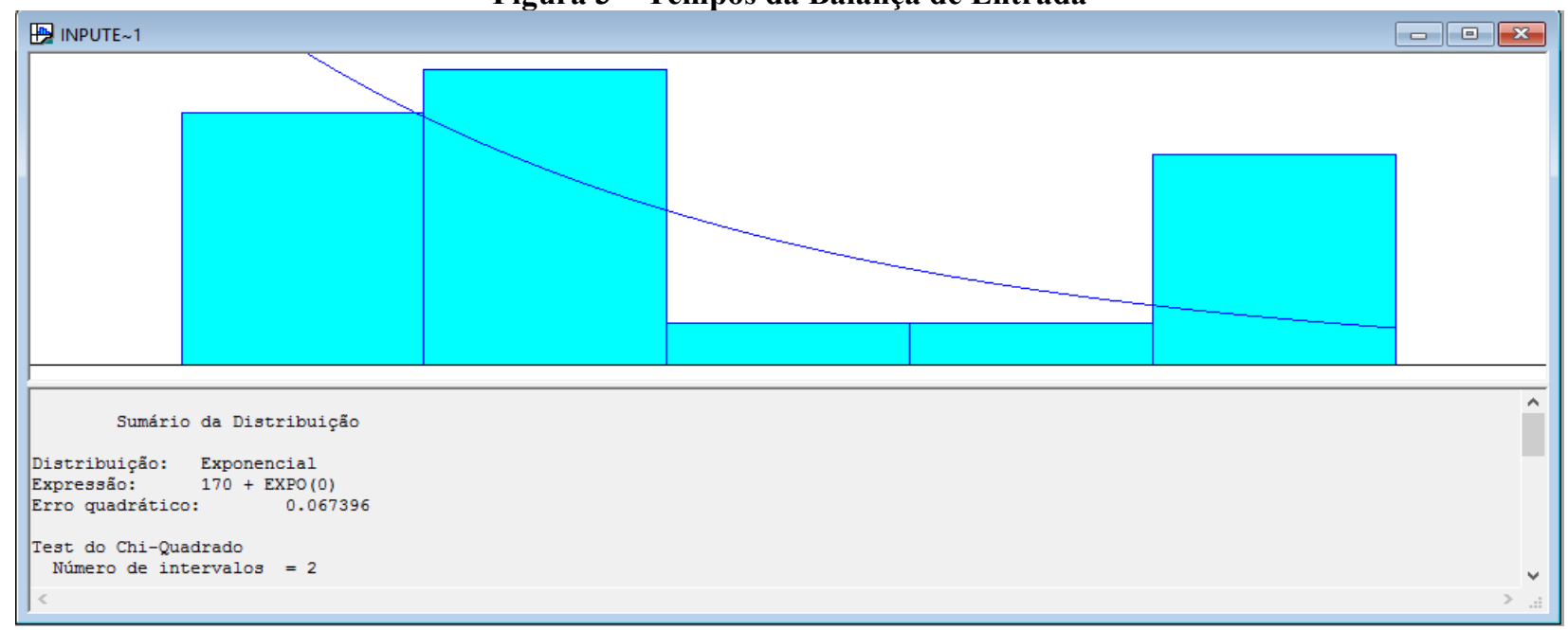

Fonte - Elaborado pelos Autores

\subsubsection{Processamento de Tempos do Furador}

Após a balança de entrada coletar o peso do caminhão, ele segue para a fila do furador, passa pela sonda onde é coletado a amostra da cana-de-açúcar para análise sendo todo esse processo automático. $\mathrm{O}$ funcionário recolhe o ticket do motorista, retira o bagaço do triturador e libera o motorista, sendo este processo manual. Apenas um funcionário faz essa função por turno e o tempo 


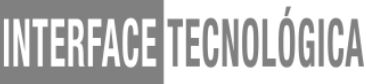

médio foi de 10 minutos para cada caminhão. Com um total de 20 tempos levantados, a expressão gerada através do Input Analyser foi: Distribuição Exponencial e Expressão $418+$ EXPO (0), conforme a figura 4.

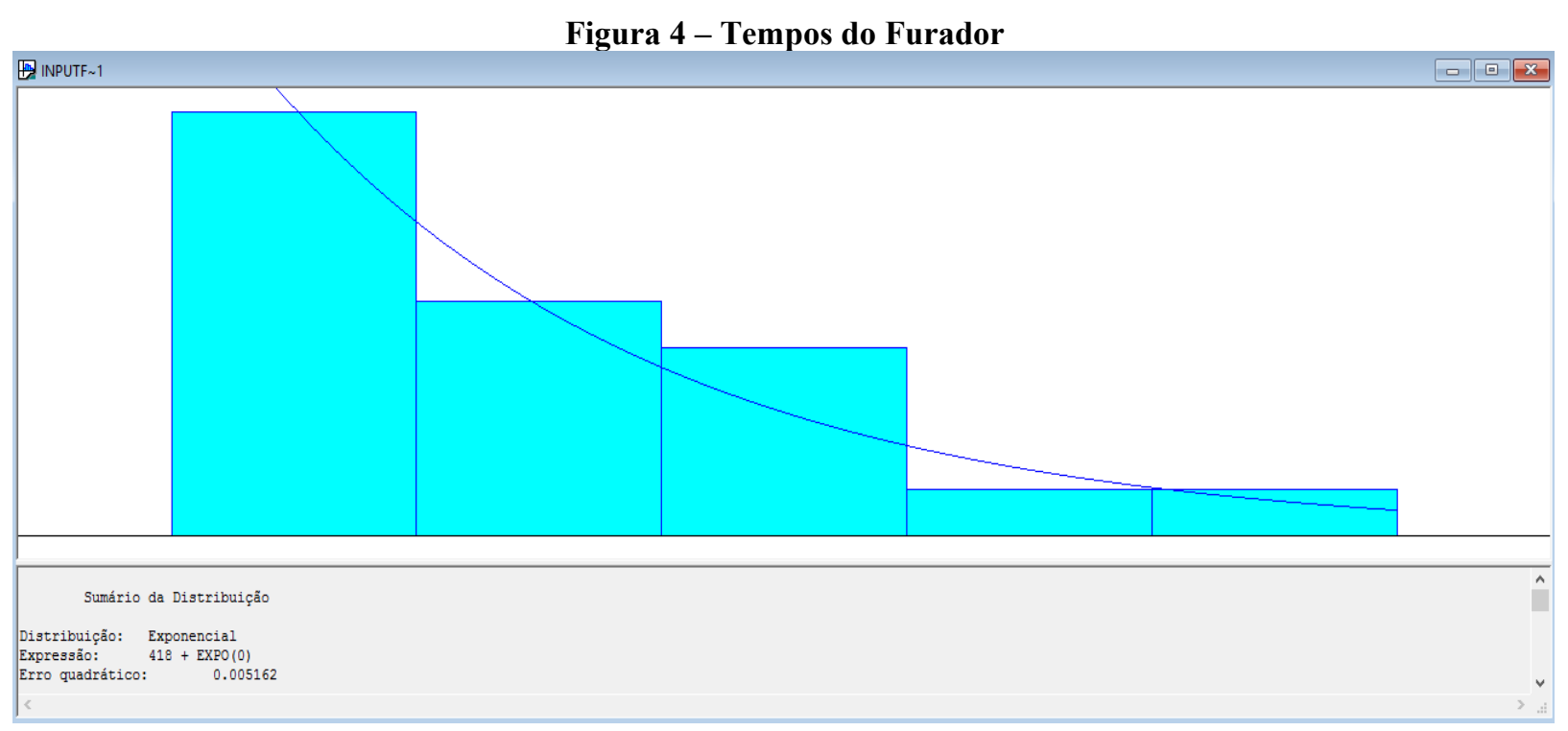

Fonte - Elaborado pelos Autores

\subsubsection{Processamento de Tempos na Mesa de descarga}

Após ser coletada a amostra para a análise, o caminhão segue para a fila da mesa de descarga, para iniciar o descarregamento da cana de açúcar. Logo após, o funcionário engata o gancho na carreta, este procedimento é manual e realizado por um funcionário por turno, o tempo médio de descarga é de 30 e 40 minutos para cada caminhão. Com um total de 20 tempos levantados, a expressão gerada através do Input Analyser foi: Distribuição Beta e Expressão $1.43 \mathrm{e}+003+2.14 \mathrm{e}+003 *$ BETA $(0,0)$, conforme a figura 5 . 
Figura 5 - Tempos da Mesa de Descarga

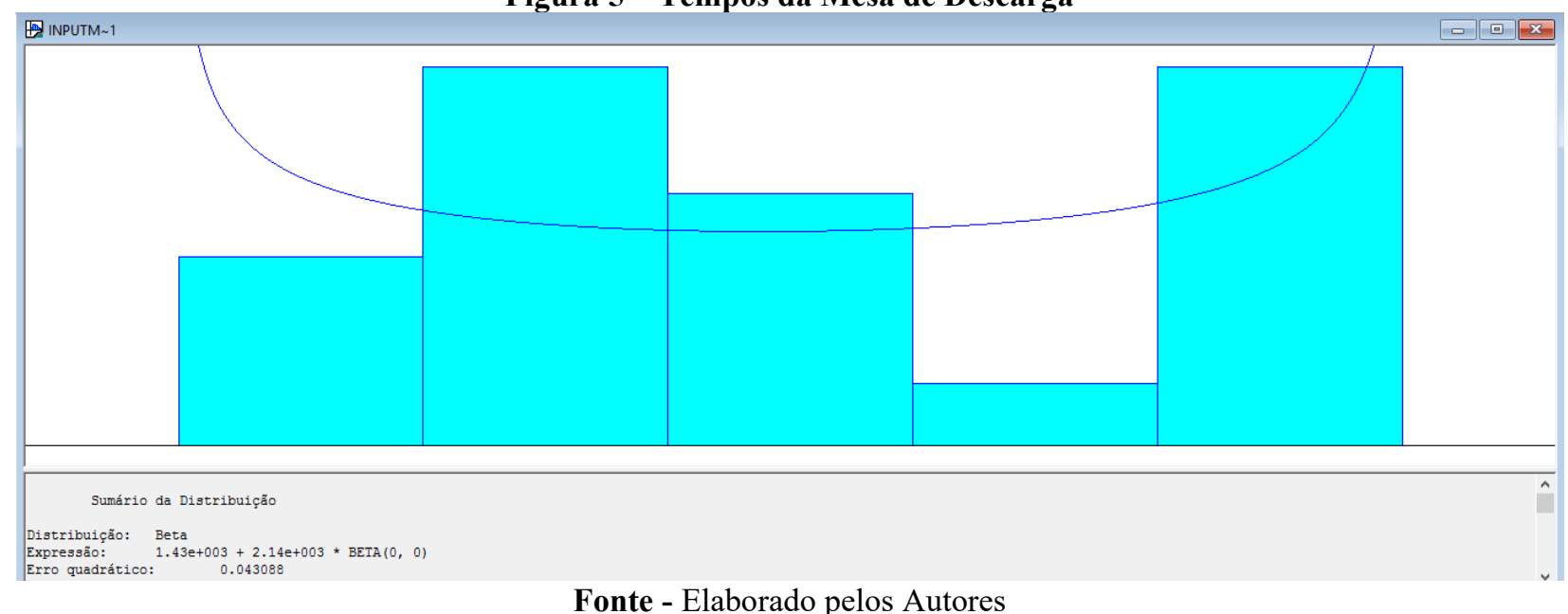

\section{RESULTADOS E DISCUSSÃO}

Baseado na simulação realizada no software ARENA, obteve-se o layout da figura 6 que representa a simulação do processo da entrada da cana de açúcar até o descarregamento da mesma, apresentando fila no setor do furador e da mesa. Esse processo, segundo a revista Novacana (2020), é o início de toda usinagem que irá resultar no açúcar e no álcool, produtos da usina.

Figura 6: Simulação rodada no software ARENA

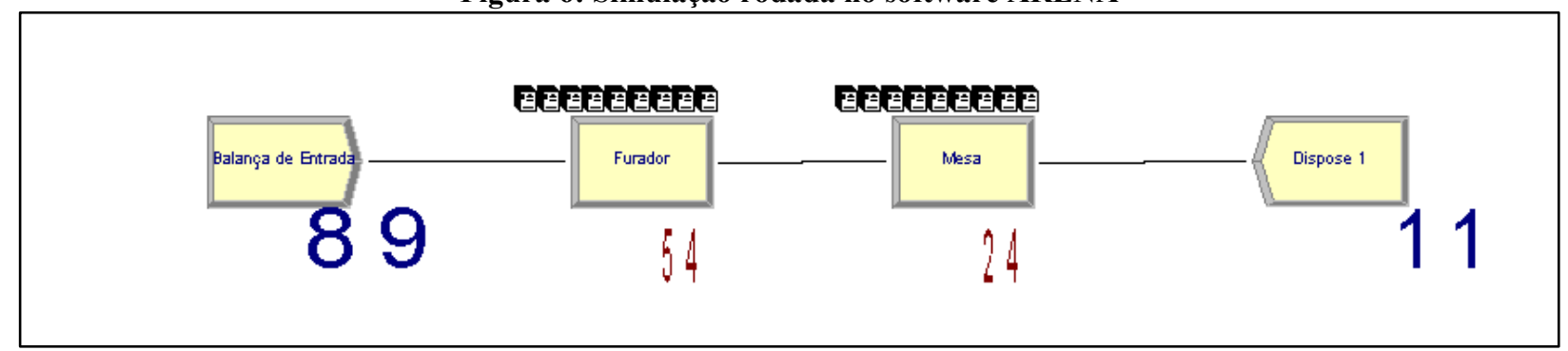

Fonte - Elaborado pelos Autores

Na figura 6 pode-se identificar 89 caminhões na balança de entrada (primeiro módulo do ARENA), passando pelo furador (segundo módulo) onde acontece um gargalo e onde ficam 54 caminhões em em fila, logo após seguindo para a mesa de descarga (terceiro módulo) onde gera uma fila de 24 caminhões, a qual é normal, pois, segundo Novacana (2020), na mesa é o processo onde se faz o tombamento do caminhão para que a cana cortada seja derrubada em uma esteira elétrica que a levará até as moendas, onde se iniciará a extração do caldo da cana. 
Nas figuras 7 e 8, tem-se o relatório de tempo e quantidade de filas em cada setor e a utilização dos funcionários nos setores respectivamente.

Figura 7 - Relatório de filas (Queues)

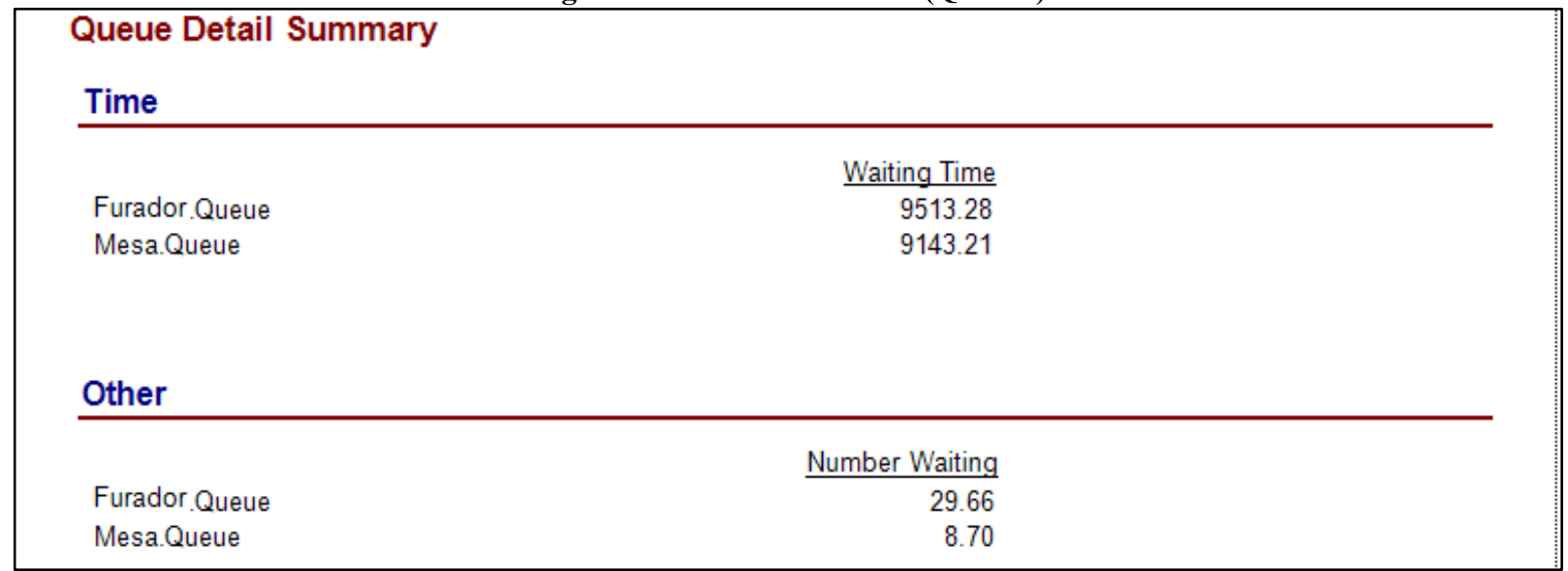

Fonte - Elaborado pelos Autores

Figura 8 - Relatório de recursos (Resources)

\begin{tabular}{|l} 
Resource Detail Summary \\
Usage \\
\begin{tabular}{lrrrrr}
\hline \\
Funcionário 1 & Inst Util & Num Busy & Num Sched & Num Seized & Sched Util \\
Funcionário 2 & 1,00 & 1,00 & 1,00 & 29,00 & 1,00 \\
\hline
\end{tabular}
\end{tabular}

Fonte - Elaborado pelos Autores

Na figura 7 tem-se dois resultados, o do tempo médio das filas (time) e o da média de caminhões que ficaram em fila (other). Pode-se notar que no setor do furador, o tempo de fila é de 9513.28 segundos e tendo em média na fila 29.66 caminhões, criando um imenso gargalo, ocasionando transtornos por falta de espaço. Na mesa de descarregamento o tempo de fila é de 9143.21 segundos e tendo em média 8.70 caminhões em espera, sendo normal caso não tenha em excesso.

Já na figura 8 tem-se o relatório de utilização dos recursos, onde foi alocado dois funcionários no sistema. No setor do furador, o "Funcionário 1" é utilizado em média 100\% (ou $1,0)$ do seu tempo de trabalho, enquanto na mesa de descarregamento, o funcionário é utilizado 98\% (ou 0,98) do tempo. Ambos os tempos de utilização são grandes, pois, segundo Prado (2014), os tempos de utilização não devem ultrapassar 85\%, pois, dessa maneira, o funcionário estaria trabalhando como uma máquina. 
Assim, ambos os setores apresentam sobrecarga de trabalho para seus funcionários, o que se sugere a alocação de mais um funcionário para cada setor e, deste modo, resolveria o problema que, segundo Ballou (2006), se caracteriza como gargalo do sistema e isso acarreta em problemas logísticos de otimização da empresa, ou seja, em fillas.

A partir deste cenário, foi proposto uma mudança na simulação vista na Figura 6, onde os autores acrescentam mais um processo de furação (Furador 2) e outra mesa de descarga (Mesa 2), com o intuito de eliminar o gargalo que foi apresentado em ambos os setores, conforme apresentado na figura 9, a fim de tentar diminuir as filas e deixar o processo mais rápido.

Figura 9- Simulação de melhoria no software ARENA

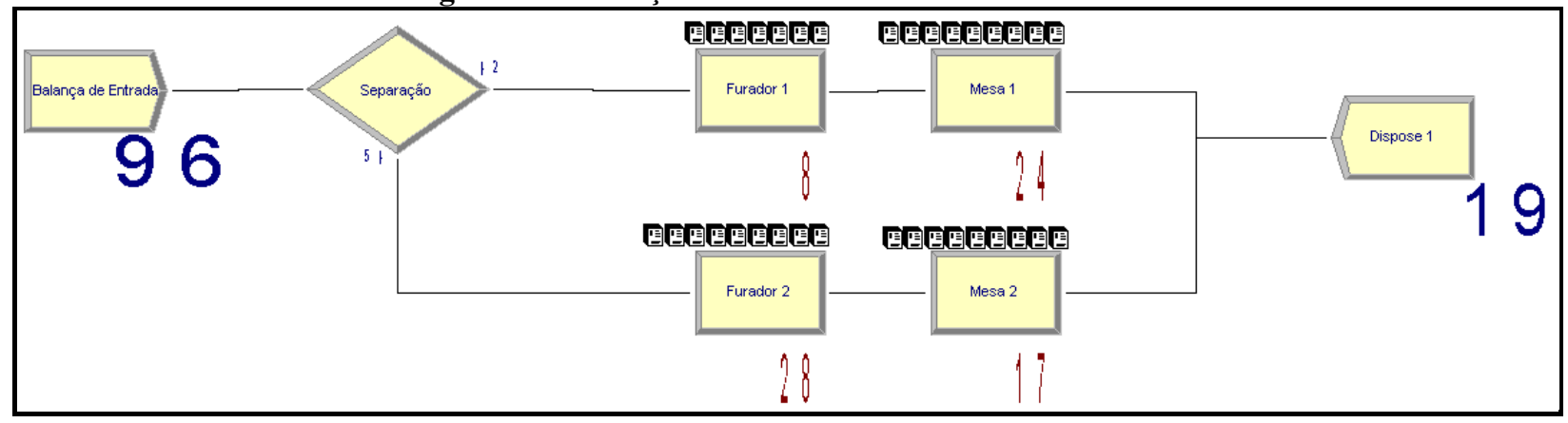

Fonte - Elaborado pelos Autores

Após a simulação ser realizada, nota-se pela Figura 9 que houve uma diminuição nas filas de ambos os setores em comparação com as apresentadas na primeira simulação, fazendo com que os setores trabalhem conforme a necessidade do processo, sem sobrecarga. Embora a Mesa 1 manteve a quantidade de filas que na primeira simulação, houve um aumento do número de caminhões entrando e saindo devido ao descarregamento na Mesa 2.

Observando-se os relatórios de filas e de utilização dos recuros, nas Figura 10 e 11 respectivamente, pode-se entender que o tempo de espera no setor dos furadores foi distribuído entre os dois e distribuídos nos dois setores da mesa de descarga, diminuindo a quantidade de caminhões em espera tanto no furador quanto na mesa de descarga, tornando o processo mais rápido.

A solução encontrada foi adicionar mais um setor de furador para atender o fluxo de entrada de cana de açúcar e mais uma mesa de descarregamento para otimizar ambos os gargalos.

Mesmo com o acréscimo desses setores, ainda é possível visualizar uma pequena fila em ambos os setores. 
A simulação, segundo Prado (2014), é um processo que representa a realidade. Assim, se houvesse espaço na área da usina para se implantar essa simulação (Figura 9), seria o ideal, mas, por falta de espaço físico não será possível adicionar mais setores.

Figura 10 - Relatório de filas (Queues)

\section{Queue Detail Summary}

Time

$\begin{array}{lr}\text { Furador 1. Queue } & \text { Waiting Time } \\ \text { Furador 2. Queue } & 2500.53 \\ \text { Mesa 1. Queue } & 2216.03 \\ \text { Mesa 2. Queue } & 8118.14 \\ & 7361.61\end{array}$

Other

Furador 1. Queue

Furador 2. Queue

Mesa 1. Queue

Number Waiting

Mesa 2. Queue

3.98
2.63
9.61
8.04

Fonte - Elaborado pelos Autores

Figura 11 - Relatório de recursos (Resources)

Resource Detail Summary

Usage

\begin{tabular}{lrrrrr} 
& Inst Util & Num Busy & Num Sched & Num Seized & Sched Util \\
\cline { 2 - 3 } Funcionário 1 & 0,93 & 0,93 & 1,00 & 34,00 & 0,93 \\
Funcionário 2 & 0,98 & 0,98 & 1,00 & 12,00 & 0,98 \\
Funcionário 4 & 0,96 & 0,96 & 1,00 & 14,00 & 0,96 \\
Funiconario 3 & 0,99 & 0,99 & 1,00 & 33,00 & 0,99
\end{tabular}

Fonte - Elaborado pelos Autores

Comparando as figuras 7 e 10, antes da proposta de melhoria, o gargalo era em média de aproximadamente $30(29,66)$ caminhões no furador era $9(8,7$ caminhões) na mesa de caminhões em fila, e após a melhoria, o gargalo caiu para a média de, no furador 1, aproximadamente 4 (3.98) caminhões, e no furador 2, 3 (2.63) caminhões e na mesa 1, aproximadamente 10 (9.6), na mesa 2, 8 caminhões em espera, porém, a fila na mesa de carregamento é normal desde que não seja em excesso. Se a proposta fosse implantada, a redução do gargalo no furador seria evidente e ajudaria em outras melhorias que necessitam ser realizadas no processo.

\section{CONSIDERAÇÕES FINAIS}

Conclui-se que o software ARENA auxiliou na sugestão de como se otimizar o processo 
de filas nos setores do furador e da mesa de descarregamento, atendendo o objetivo do artigo e demonstrou que a empresa, deveria investir em tais recursos a mais, mesmo que seja necessário a construção de outra entrada para seu processo, pois a entrada atual não possui espaço físico para tal implementação.

Sugere-se um estudo, como continuação desse artigo, para se encontar outra área próxima à empresa para essa implementação e a realização de uma nova simulação para averiguar se essa área será ótima para o processo de entrada.

\section{REFERÊNCIAS}

ARALDI, A. A. R. Ensino Simulação de Sistemas. Revista Ensino e Educação, 2013. Acesso em: $<$ https://www.ensinoeinformacao.com/simulao-com-arena $>$. Acesso em: 10 mar. 2020.

BALLOU, R. H. Gerenciamento da Cadeia de Suprimentos/ Logística Empresarial. 5. ed. Porto Alegre: Bookman, 2006.

COSTA, M. A. B. E PEREIRA, C. R. Apostila ARENA 11.0. UfSCar: São Carlos, 2009.

HERCULANI, R. et al. Aplicação do Software ARENA em uma Fabrica de Pães Congelados. REVISTA FATEC SEBRAE EM DEBATE: Gestão, Tecnologias e Negócios, 2017.

NOVACANA. Cana de açúcar - Tudo sobre esta versátil planta. 2013. Disponível em: $<$ https://www.novacana.com/cana-de-acucar $>$. Acesso em: 19 nov. 2019.

. Como é feito o processamento da cana-de-açúcar nas usinas. Disponível em: $<$ https://www.novacana.com/usina/como-e-feito-processamento-cana-de-acucar $>$. Acesso em: 10 fev. 2020.

PRADO, D. Usando o ARENA em simulação. 4.ed. Nova Lima: INDG LTDA, 2010.

. Usando o ARENA em Simulação. 5. ed. Minas Gerais: Falconi, 2014. V.3.

YARABRASIL. Produção mundial de cana-de-açúcar. Disponível em:

$<$ https://www.yarabrasil.com.br/nutricao-de-plantas/cana-de-acucar/producao-mundial-decana/>. Acesso em: 10 fev. 2020.

WIKIPEDIA. Rockwell Arena. Disponível em:

$<$ https://pt.wikipedia.org/wiki/Rockwell_Arena>. Acesso em 10 fev. 2020. 